\title{
In vitro and in vivo antimicrobial activity of combined therapy of silver nanoparticles and visible blue light against Pseudomonas aeruginosa
}

This article was published in the following Dove Press journal:

International Journal of Nanomedicine

27 April 2016

Number of times this article has been viewed

\author{
Suzanne Nour El Din' \\ Tarek A El-Tayeb ${ }^{2}$ \\ Khaled Abou-Aisha' \\ Mohamed El-Azizi ${ }^{1}$ \\ 'Department of Microbiology, \\ Immunology and Biotechnology, \\ Faculty of Pharmacy and \\ Biotechnology, German University in \\ Cairo, ${ }^{2}$ National Institute for Laser \\ Enhanced Sciences, Cairo University, \\ Cairo, Egypt
}

\begin{abstract}
Silver nanoparticles (AgNPs) have been used as potential antimicrobial agents against resistant pathogens. We investigated the possible therapeutic use of AgNPs in combination with visible blue light against a multidrug resistant clinical isolate of Pseudomonas aeruginosa in vitro and in vivo. The antibacterial activity of AgNPs against $P$. aeruginosa $\left(1 \times 10^{5}\right.$ colony forming unit $/ \mathrm{mL}$ ) was investigated at its minimal inhibitory concentration (MIC) and sub-MIC, alone and in combination with blue light at $460 \mathrm{~nm}$ and $250 \mathrm{~mW}$ for 2 hours. The effect of this combined therapy on the treated bacteria was then visualized using transmission electron microscope. The therapy was also assessed in the prevention of biofilm formation by $P$. aeruginosa on AgNP-impregnated gelatin biopolymer discs. Further, in vivo investigations were performed to evaluate the efficacy of the combined therapy to prevent burn-wound colonization and sepsis in mice and, finally, to treat a real infected horse with antibiotic-unresponsive chronic wound. The antimicrobial activity of AgNPs and visible blue light was significantly enhanced $(P<0.001)$ when both agents were combined compared to each agent alone when AgNPs were tested at MIC, $1 / 2$, or $1 / 4$ MIC. Transmission electron microscope showed significant damage to the cells that were treated with the combined therapy compared to other cells that received either the AgNPs or blue light. In addition, the combined treatment significantly $(P<0.001)$ inhibited biofilm formation by $P$. aeruginosa on gelatin discs compared to each agent individually. Finally, the combined therapy effectively treated a horse suffering from a chronic wound caused by mixed infection, where signs of improvement were observed after 1 week, and the wound completely healed after 4 weeks. To our knowledge, this combinatorial therapy has not been investigated before. It was proved efficient and promising in managing infections caused by multidrug resistant bacteria and could be used as an alternative to conventional antibiotic therapy.
\end{abstract}

Keywords: biofilm, invasive sepsis, wound colonization, murine model, bioplastic disc, nonconventional therapy

\section{Introduction}

Metallic silver, silver nitrate, and silver sulfadiazine have been used in the treatment of a wide range of infections, ${ }^{1}$ their use, however, had been diminished with the start of the antibiotic era. Since most pathogenic bacteria continuously develop resistance to most available antibiotics, silver nanoparticles (AgNPs) have been reconsidered as a potential alternative to conventional antimicrobial agents.

AgNPs can be incorporated into antimicrobial applications, such as bandages, surface coatings, medical equipment, food packaging, functional clothes, and cosmetics. ${ }^{2}$ It has been estimated that 320 tons of nanosilver are used annually, ${ }^{3}$ with $30 \%$ of all currently registered nanoproducts containing nanosilver. ${ }^{4}$ Metallic silver 
is a potential biocide that has been reported to be less toxic compared to silver ions. ${ }^{5}$

Visible blue light is recently attracting increasing attention as an alternative to traditional antibiotics as a novel light-based antimicrobial agent. It does not involve the use of exogenous photosensitizers as in the photodynamic therapy, and is less damaging to mammalian cells than ultraviolet irradiation. ${ }^{6}$ Blue light has been reported to have significant antimicrobial activity against a broad range of bacterial and fungal pathogens. ${ }^{6,7}$

The rate of emergence of antibiotic resistance has increased dramatically due to antibiotic misuse, the failure of some patients to comply with their treatment regimen, and the high capability of bacteria to mutate. As a result, antibiotic resistance leads to the failure of treatment of life-threatening bacterial infections and increases costs due to longer stay in health care settings. ${ }^{8,9}$

The use of nonconventional therapy to which bacteria are improbable to develop resistance would be the best alternative.

The aim of this work is to investigate the therapeutic application of AgNPs in combination with blue light against Pseudomonas aeruginosa. To our knowledge, this is the first study that investigates this combined therapy against bacterial infections both in vitro and in vivo.

\section{Materials and methods}

Unless otherwise indicated, all chemicals (analytical grade) were purchased from Sigma-Aldrich, St Louis, MO, USA. Prior to the start of the animal experiments, ethical and legal approval was obtained from the Faculty of Pharmacy and Biotechnology Committee for Care and Use of Animals. The use of the combined therapy to treat real infection in the horse was approved by the Faculty of Pharmacy and Biotechnology Ethics Committee decision \# 56-2011.

\section{Microorganism}

A multidrug resistant (MDR) clinical isolate of $P$. aeruginosa was used in the study. The isolate was identified to the species level by using standard microbiological techniques. The microorganism was found to be resistant to ciprofloxacin, ceftazidime, piperacillin, and imipenem.

\section{Preparation of AgNPs}

The AgNPs were prepared as previously described by Métraux and Mirkin. ${ }^{10}$ Briefly, $75 \mathrm{~mL}$ from a $0.01 \mathrm{M}$ stock solution of silver nitrate was added to $10 \mathrm{~mL}$ of an aqueous solution containing $0.08 \mathrm{~g}$ sodium citrate and $0.2 \mathrm{~g}$ polyvinylpyrrolidone. Ten $\mathrm{mL}$ of $0.05 \mathrm{M}$ sodium borohydride was added to the mixture all at once, and the volume made up to $100 \mathrm{~mL}$ using distilled water. The solution turned dark brown indicating the conversion of silver nitrate to AgNPs. The final concentration of AgNPs was $0.862 \mathrm{mg} / \mathrm{mL}$. Higher concentrations of the AgNPs can be obtained by increasing the concentration of the starting material, silver nitrate.

The nanoparticles were characterized spectrophotometrically, where a surface plasmon resonance peak appeared between 390 and $410 \mathrm{~nm} .{ }^{11}$ The particles size was characterized by Malvern Zetasizer Nano ZS (Malvern Instruments Ltd, Malvern, UK) and Tecnai G20, Super twin, double tilt ultra-high resolution transmission electron microscope (FEI Tecni, Hillsboro, OR, USA), which showed a uniform distribution of the nanoparticles, with an average size of $15-20 \mathrm{~nm}$.

\section{Determination of MIC and MBC of AgNPs against $P$. aeruginosa}

The minimal inhibitory concentration (MIC) was determined based on the guidelines of the Clinical Laboratory Standard Institute. ${ }^{12}$ The minimum bactericidal concentration (MBC) was determined by taking $10 \mu \mathrm{l}$ samples from MIC well, and from wells with higher concentrations, and streaked onto the surface of Muller Hinton agar plates. After a 24-hour incubation, the number of colony forming units (CFU) per $\mathrm{mL}$ was counted and the $\mathrm{MBC}$, defined as the concentration that kills $99.9 \%$ of bacteria, was determined.

\section{Antimicrobial activity of AgNPs in combination with visible blue light against $P$. aeruginosa in vitro}

The effects of AgNPs were investigated in combination with visible blue light against the clinical isolate of P. aeruginosa. The AgNP preparation was tested at its MIC and sub-MICs $(1 / 2,1 / 4,1 / 8,1 / 16,1 / 32,1 / 64$, and 1/128 of the MIC) in 24-well plates. Briefly, bacterial suspensions were pipetted into the wells, which contained the AgNPs at the tested concentrations in Muller Hinton Broth (MHB) to give an initial inoculum density of $1 \times 10^{5} \mathrm{CFU} / \mathrm{mL}$ and a final volume of $2 \mathrm{~mL} /$ well. The wells were exposed to a photon emitting diode (Photon Scientific, Cairo, Egypt) at $460 \mathrm{~nm}$ and $250 \mathrm{~mW}$ for 2 hours. Samples were taken after $0,2,4,6$, and 8 hours of inoculation, where viable bacteria were determined by viable count technique. Briefly, $10 \mu \mathrm{L}$ aliquots were withdrawn and spread onto nutrient agar plates. The plates were incubated for 24 hours at $37^{\circ} \mathrm{C}$. The same procedure was repeated with AgNP- and light-free wells. The experiment was performed in triplicates and the results were compared to drug-free samples. 


\section{Visualization of the effect combination of AgNPs and blue light on $P$. aeruginosa using TEM}

Ten $\mathrm{mL}$ of MHB was inoculated with $1 \times 10^{5} \mathrm{CFU} / \mathrm{mL}$ of $P$. aeruginosa in $15 \mathrm{~mL}$ conical centrifuge tubes (Falcon, Corning, NY, USA) before being incubated at $37^{\circ} \mathrm{C}$ for 4 hours, until the bacteria reached the logarithmic phase. The suspensions were then centrifuged at $2.800 \times g$ for 10 minutes, then the cell pellets were resuspended in $10 \mathrm{~mL}$ of fresh $\mathrm{MHB}$ containing $8 \mathrm{mg} / \mathrm{mL}$ of AgNPs. Two $\mathrm{mL}$ portions of the suspension were transferred to 24-multiwell plates. The plates were incubated at room temperature during which the wells were exposed to the blue light at $460 \mathrm{~nm}$ for 2 hours using the photon emitting diode. One $\mathrm{mL}$ samples were then taken and prepared for transmission electron microscope (TEM) as previously described. ${ }^{13}$ Briefly, the samples were centrifuged and the bacterial pellets were fixed in $1 \mathrm{~mL}$ of $3 \%$ glutaraldehyde for 2 hours and then centrifuged and washed with $7.2 \%$ phosphate buffer. A secondary fixative, osmium tetraoxide, was then added to the pellets, and incubated for 1 hour before being washed with phosphate-buffered saline. The samples were then subjected to a series of dehydration steps using different concentrations of ethanol, starting with ethanol 50\% to $95 \%$. During each step, the samples were left for 10 minutes before finally being put in absolute ethanol for 20 minutes. The samples were then embedded in resin blocks that were subsequently cut into semi- to ultra-thin $(60 \mathrm{~nm})$ thickness and finally stained with uranyl acetate and lead citrate before being examined by TEM. The same procedure was repeated for bacterial cultures treated with AgNPs, blue light, or both. The results were compared to drug- and light-free control experiments.

\section{Antimicrobial effect of combined AgNPs and blue light on biofilm formation by $P$. aeruginosa on gelatin-based bioplastic discs}

The gelatin-based bioplastic discs were prepared in our laboratory. Briefly, $4 \mathrm{~g}$ of gelatin was dissolved in $40 \mathrm{~mL}$ distilled water. Two $\mathrm{mL}$ of formaldehyde was then added and the mixture was stirred for 4 hours. The AgNPs were added to the mixture to give a final concentration of $8 \mathrm{mg} / \mathrm{mL}$ followed by addition of $20 \mathrm{~mL}$ glycerin as a plasticizer and the final volume was made up to $100 \mathrm{~mL}$ using distilled water. The solution was degassed under vacuum until a clear bubble-free solution was obtained. The mixture was then poured into Petri dishes and left to dry at $45^{\circ} \mathrm{C}$ for 24 hours. The formed gelatin sheets were then aseptically punched out using a sterile cork borer to give $1 \mathrm{~cm}$ diameter discs. To get rid of formaldehyde, the discs were washed in sterile distilled water and then left to dry under laminar flow.

The rate of the release of nanoparticles from the gelatin disc was determined by placing the discs in $10 \mathrm{~mL}$ aliquots of distilled water and daily samples were taken and the characteristic peak at $400 \mathrm{~nm}$ was monitored spectrophotometrically over a period of 14 days.

The efficacy of AgNPs impregnated in the gelatin discs with or without combination with the blue light to prevent biofilm formation of $P$. aeruginosa was evaluated. Briefly, the unloaded or loaded discs with AgNPs were placed in the wells of 24-multiwell plates. One $\mathrm{mL}$ portions of sterile MHB containing $1 \times 10^{7} \mathrm{CFU} / \mathrm{mL}$ of $P$. aeruginosa were delivered into the wells before being exposed to blue light for 2 hours, and the plates were then incubated for 24 hours at $37^{\circ} \mathrm{C}$. The discs were washed twice with $2 \mathrm{~mL}$ of sterile phosphate-buffered saline to remove planktonic cells. To dislodge adherent cells, the discs were placed in pre-cooled saline, and sonicated using Bandelin Sonoplus HD 2070 Ultrasonic Homogenizer (BANDELIN electronic $\mathrm{GmbH}$ \& Co. KG, Berlin, Germany) at a continuous sonication cycle set at the maximum output for 30 seconds. The viable count of the dislodged bacterial cells was then determined. The same experiment was repeated in the presence of either AgNPs or blue light and the results were compared to control experiment in which the biofilm was formed on unloaded disc without blue light exposure.

\section{Effect of AgNPs in combination with blue light on wound colonization and invasive sepsis by $P$. aeruginosa in a murine model}

All procedures and guidelines of the Institutional Animal Care and Use Committee were strictly followed. Seven groups each of five male Swiss mice were used as described in Table 1. Bacteria were grown in Tryptic Soya Broth medium for 18 hours at $37^{\circ} \mathrm{C}$. Culture suspensions were centrifuged at

Table I The groups of mice and the corresponding treatment they received

\begin{tabular}{llllll}
\hline Group & Burn & Bacteria & Light & AgNPs & Silver sulfadiazine \\
\hline $\mathrm{I}$ & - & - & - & - & - \\
$\mathrm{II}$ & + & - & - & - & - \\
$\mathrm{III}$ & + & + & - & - & - \\
$\mathrm{IV}$ & + & + & + & - & - \\
$\mathrm{V}$ & + & + & - & + & - \\
$\mathrm{VI}$ & + & + & - & - & + \\
$\mathrm{VII}$ & + & + & + & + & - \\
\hline
\end{tabular}

Notes: (-) no treatment received; (+) treatment received. Group III received silver nanoparticle (AgNP)-free gel preparation. 
$7,000 \times g$ for 15 minutes, washed twice in sterile phosphatebuffered saline, and finally standardized to $10^{8} \mathrm{CFU} / \mathrm{mL}$. The animals were anesthetized using intraperitoneal injection of $60 \mathrm{mg} / \mathrm{kg}$ pentobarbital, and a full thickness scalded wound was produced on the animals' dorsum by exposing $4 \mathrm{~cm}^{2}$ area of their shaved skin to $100^{\circ} \mathrm{C}$ water for 30 seconds. All animals received $5 \mathrm{mg} / \mathrm{kg}$ of ketoprofen subcutaneously every 12 hours. The animals were infected with $1 \mathrm{~mL}$ of the bacterial suspension.

The AgNPs in hydroxypropylmethyl cellulose (K200M) gel preparation were formulated as previously described by Rupal et al. ${ }^{14}$ Briefly, hydroxypropylmethyl cellulose (3.5 g) was dispersed in $90 \mathrm{~mL}$ distilled water with continuous stirring using a magnetic stirrer at a moderate speed (500 rpm) for $\sim 2$ hours. Calculated amounts of AgNPs were mixed to homogeneity to produce a final concentration of $8 \mathrm{mg} / \mathrm{g}$ using Wiggen Hauser D500 Homogenizer (Wiggenhauser Mashinenbau, Berlin, Germany). The prepared gel was packed in a wide-mouthed container and kept stored at $4^{\circ} \mathrm{C}$ until used.

The topical treatment with AgNPs at $8 \mathrm{mg} / \mathrm{g}$ was applied 2 hours after bacterial inoculation and then once daily for 2 days. On the third day, the mice were euthanized and $1 \mathrm{~cm}^{2}$ of the burn wounds, kidney, lung, and liver were aseptically collected and homogenized. Briefly, specimens were suspended and homogenized in $5 \mathrm{~mL}$ precooled saline solution by sonication at a continuous sonication cycle set at the maximum output for 30 seconds. One $\mathrm{mL}$ samples were then serially diluted in MHB, spread onto the surface of nutrient agar plates, incubated at $37^{\circ} \mathrm{C}$ for 24 hours, and viable colony counts were recorded.

\section{Efficacy of the combined therapy of $\mathrm{AgNPs}$ with blue light in the treatment of antibiotic-unresponsive chronic wound in an infected horse}

A 13-year-old female thoroughbred horse suffering from a chronic skin wound on its back was treated with AgNPs in combination with blue light. The horse is the property of Al Shams Sporting Club, Cairo, Egypt, and is used for training horse riders. Initial examination of the animal showed a wound with inflamed, red, and swollen tissues with exudates and blood. The wound resulted from the friction with the saddle, which resulted in a skin cut. The surrounding dusty and humid environment exacerbated the wound condition and promoted bacterial infection. The medical record of the horse indicated that it received a topical treatment regimen composed of oxytetracycline hydrochloride aerosol, $40 \mathrm{mg}$, in combination with gentian violet paint for 2 weeks.
Following the topical treatment, Pentstrep-400, a combined injection consisting of procaine penicillin $(200 \mathrm{mg})$ and dihydrostreptomycin sulfate $(200 \mathrm{mg})$, was given as $1 \mathrm{~mL}$ per $10 \mathrm{~kg}$ body weight every day for 2 weeks. The course of treatment with topical and systemic antibiotics was repeated several times with no sign of improvement.

A swab was taken from the wound and spread onto the surface of a blood agar plate. After 24-hour incubation at $37^{\circ} \mathrm{C}$, the growing colonies were identified by Gram staining and standard microbiological techniques.

The AgNPs at $16 \mathrm{mg} / \mathrm{g}$ were formulated in hydroxypropylmethyl cellulose gel preparation as described above. The gel was applied to the infected wound every 12 hours for 3 weeks. Each dose was followed by application of blue light to the wound for 20 minutes using the blue light emitting diode. The course of treatment was repeated with one dose of the drug followed by application of the blue light every 24 hours till the complete healing of the wound. A swab was taken every week for bacterial subculture.

\section{Statistical analysis}

Each experiment was performed in quadruplicate and the mean and standard deviation were calculated. One-way analysis of variance was used to determine the differences between various treatments. Tukey's pair comparison test was used at the chosen level of probability $(P<0.05)$ to determine significant difference between means.

\section{Results}

\section{Antimicrobial activity of AgNPs in combination with blue light against $P$. aeruginosa in vitro}

The MIC and MBC of AgNPs against the tested isolate were found to be $8 \mathrm{mg} / \mathrm{mL}$. The antimicrobial activity of AgNPs at their MIC was significantly enhanced $(P<0.001)$ in combination with blue light compared to each of them alone (Figure 1), where all bacteria were killed after 2 hours of exposure to the combined therapy. Although this enhancement was also observed when the compound was tested at $1 / 2$ and $1 / 4$ of its $\mathrm{MIC}$, longer exposure times were needed to kill all bacteria. At lower concentrations of the AgNPs, the effect was insignificant compared to the drug-free control and each agent alone.

\section{TEM examination of $P$. aeruginosa after combined treatment with AgNPs and blue light}

The effects of the AgNPs administered alone or in combination with a 2-hour exposure to blue light on $P$. aeruginosa 
A

MIC

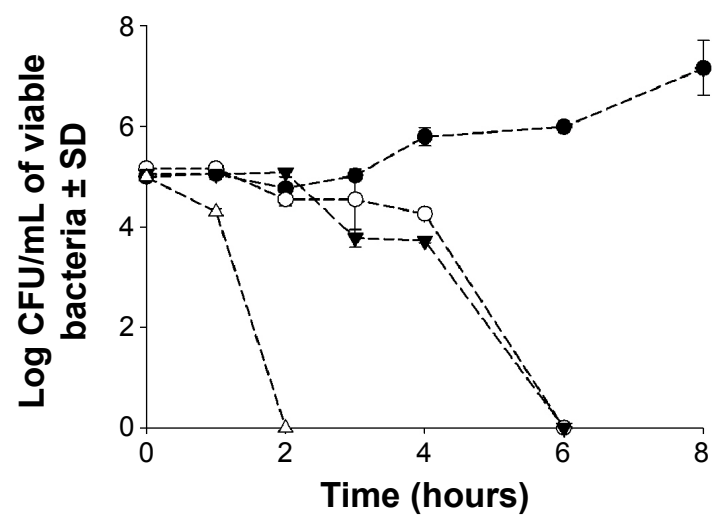

C

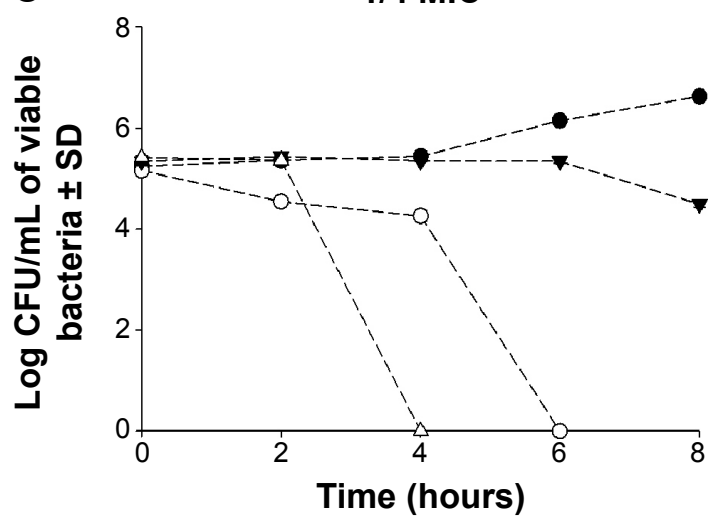

B

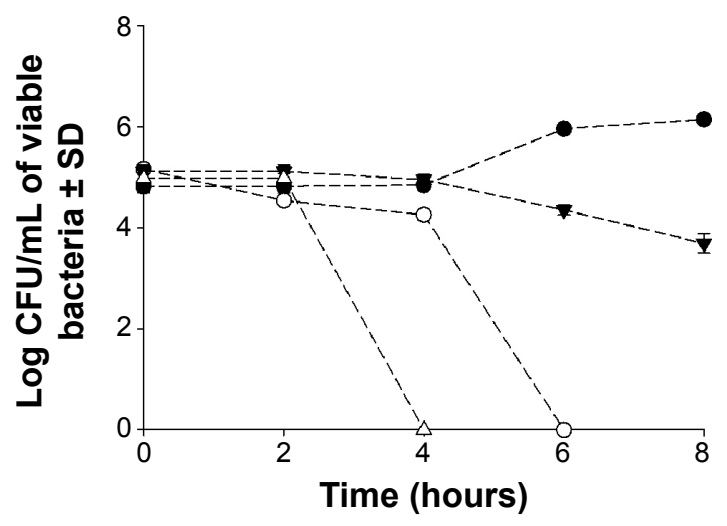

D

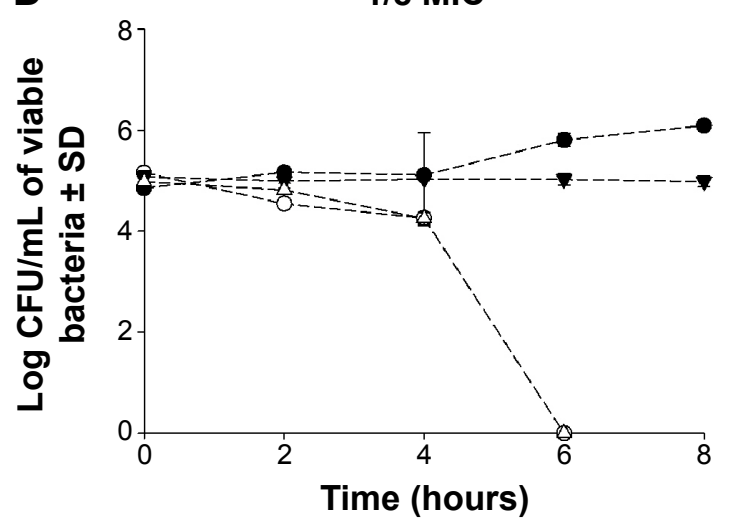

- Control -O- Blue light only - - - AgNPs only $-\triangle$ - AgNPs + Blue light

Figure I Antimicrobial activity of silver nanoparticles (AgNPs) in combination with blue light against Pseudomonas aeruginosa.

Notes: Cell suspensions were exposed to either the silver compound alone at minimal inhibitory concentration (MIC) and sub-MIC, blue light alone at $460 \mathrm{~nm}$ and $250 \mathrm{~mW}$ for 2 hours, or a combination of both agents. Viable colony count was recorded as the mean of three separate experiments. Note that the combination enhanced the antimicrobial activity of both agents when the AgNPs were tested at MIC (A), I/2 MIC (B), and I/4 MIC (C), but not at I/8 MIC (D).

Abbreviations: CFU, colony forming unit; SD, standard deviation.

were investigated using TEM (Figure 2). As shown in the figure, blue light had no visible effects on the bacterial cells, which remained intact after the indicated exposure period. On the other hand, bacteria treated with AgNPs showed signs of membrane damage and partial release of chromosomal fragments. Bacteria treated with a combination of both agents were severely affected with most cells lysed at the end of the experiment.

\section{Effect of the combined antimicrobial therapy of AgNPs and blue light in preventing biofilm formation by $P$. aeruginosa on gelatin-based bioplastic discs}

The combined therapy significantly $(P<0.001)$ reduced the number of adherent cells $\left(\log _{10} \mathrm{CFU} / \mathrm{mL}\right.$ reduction $\left.=9.8\right)$ of the biofilm of $P$. aeruginosa on the gelatin-based discs compared to the silver compound $\left(\log _{10} \mathrm{CFU} / \mathrm{mL}\right.$ reduction $=7.9)$ or the blue light alone $\left(\log _{10} \mathrm{CFU} / \mathrm{mL}\right.$ reduction $=0)($ Figure 3$)$.

\section{Effect of AgNPs in combination with blue light in preventing wound colonization and invasive sepsis by $P$. aeruginosa in a murine model}

Combination of AgNPs with blue light significantly $(P<0.001)$ reduced the number of bacteria in the wounded skin while the effect of other treatments was insignificant compared to untreated animals (Figure 4). Dissemination of the infection to internal organs was significantly $(P<0.001)$ diminished in the liver following the treatment with blue light, AgNPs alone, or the combined therapy, while such an effect was not observed in other organs. 

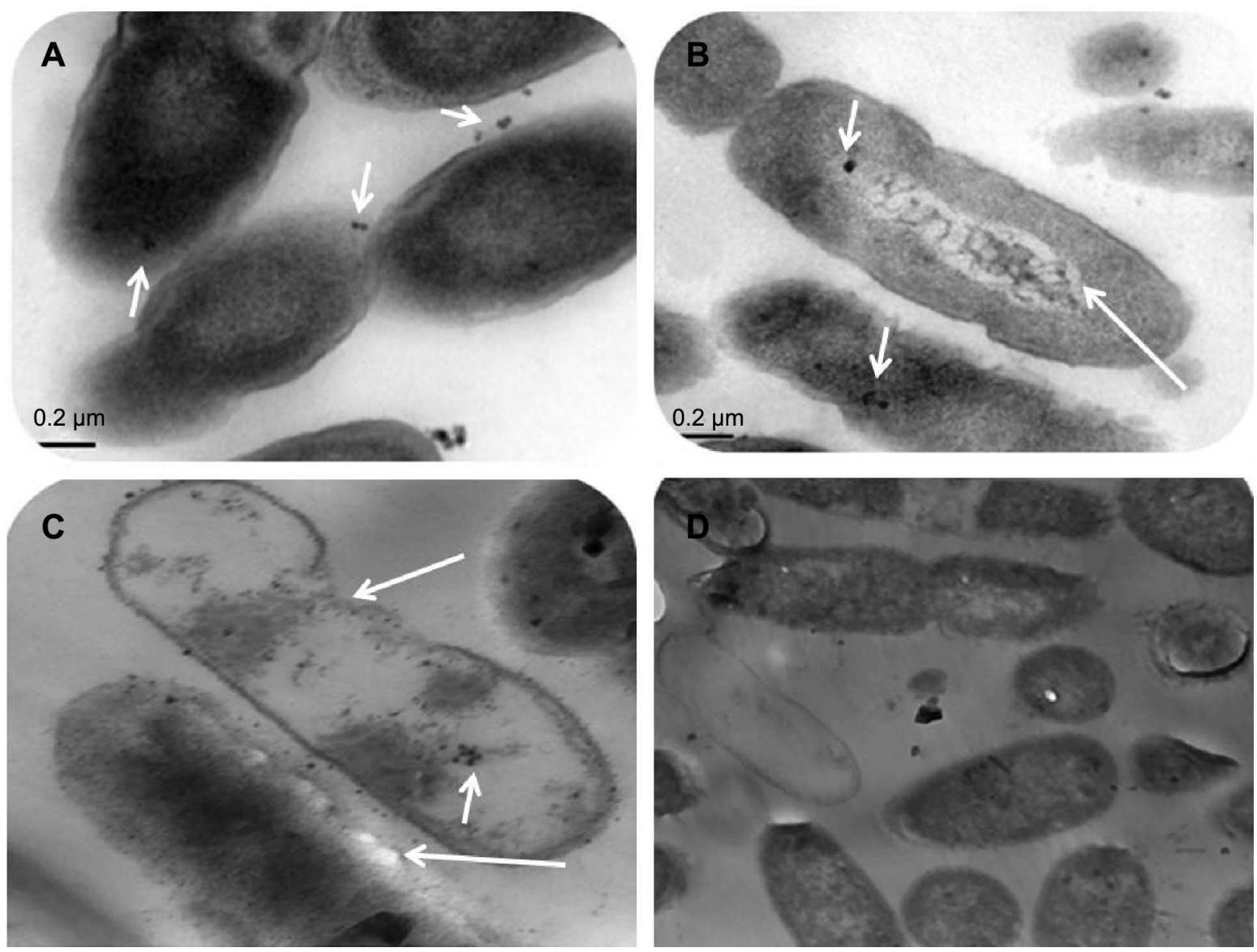

Figure 2 Visualization of the effect of combination of silver nanoparticles (AgNPs) and blue light on Pseudomonas aeruginosa using transmission electron microscopy.

Notes: The bacterial cells in Mueller Hinton Broth medium were treated as follows: (A) $8 \mathrm{mg} / \mathrm{mL}$ AgNPs alone at zero time. (B) $8 \mathrm{mg} / \mathrm{mL}$ AgNPs alone after 2 hours. (C) $8 \mathrm{mg} / \mathrm{mL} \mathrm{AgNPs} \mathrm{in} \mathrm{combination} \mathrm{with} \mathrm{blue} \mathrm{light} \mathrm{for} 2$ hours. (D) Blue light alone after 2 hours of exposure. Note that at zero time most of AgNPs adhered to the cell surfaces whereas the majority entered the cells after 2 hours. Prominent damage is clear in cells that received the combined therapy compared to other cells which received each treatment alone. Small arrows indicate the location of the AgNPs and long arrows show the cellular damage.

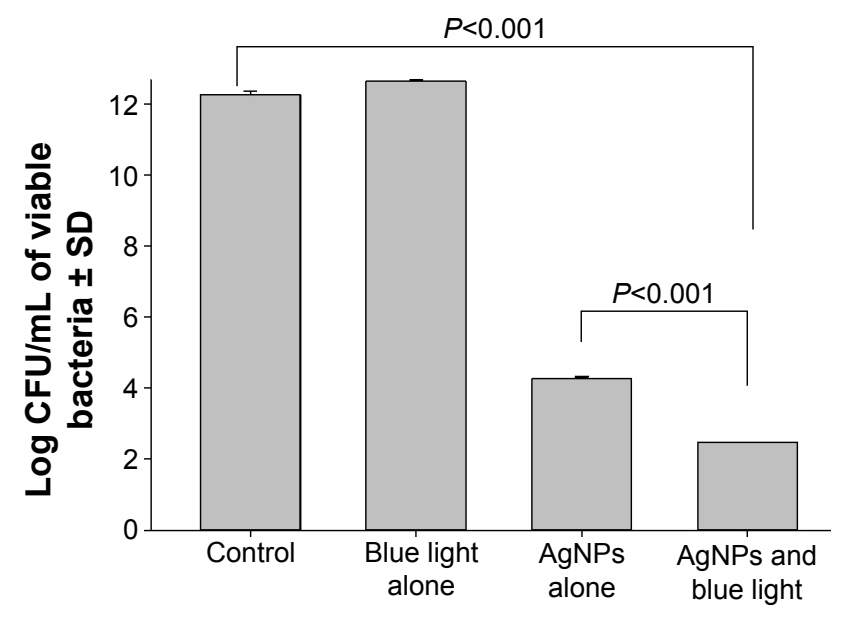

Figure 3 Effect of the combined antimicrobial therapy of silver nanoparticles (AgNPs) and blue light in preventing biofilm formation by Pseudomonas aeruginosa on gelatin-based bioplastic discs.

Notes: AgNP-impregnated gelatin discs with or without combination with the blue light were inoculated with $1 \times 10^{7} \mathrm{CFU} / \mathrm{mL}$ of $P$. aeruginosa. The formed biofilm was then dislodged by sonication and the viable adherent cells were counted. Viable colony count was recorded as the mean of three separate experiments. Note that the combined therapy significantly reduced the number of adherent cells in the biofilm compared to the control and the silver compound or blue light alone. Error bars represent SD. Abbreviations: CFU, colony forming unit; SD, standard deviation.

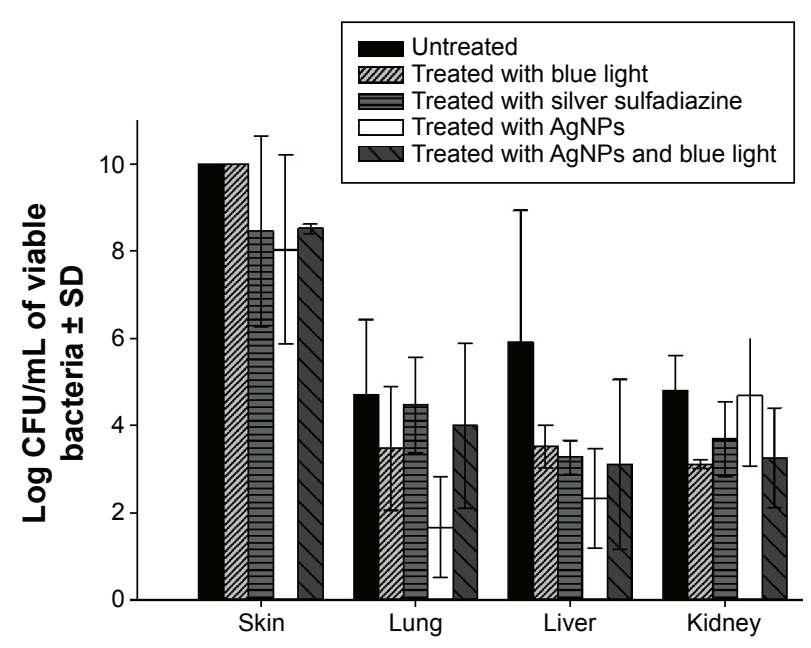

Figure 4 Effect of silver nanoparticles (AgNPs) in combination with blue light in preventing wound colonization and invasive sepsis by Pseudomonas aeruginosa in a murine model.

Notes: The AgNPs at $8 \mathrm{mg} / \mathrm{mL}$, alone and in combination with blue light, were tested to prevent burn wound infection and dissemination by $P$. aeruginosa. The combined therapy was more effective to reduce the bacterial load in the wound compared to other treatments; other treatments failed to prevent dissemination to internal organs except to the liver. Error bars represent SD.

Abbreviation: SD, standard deviation. 

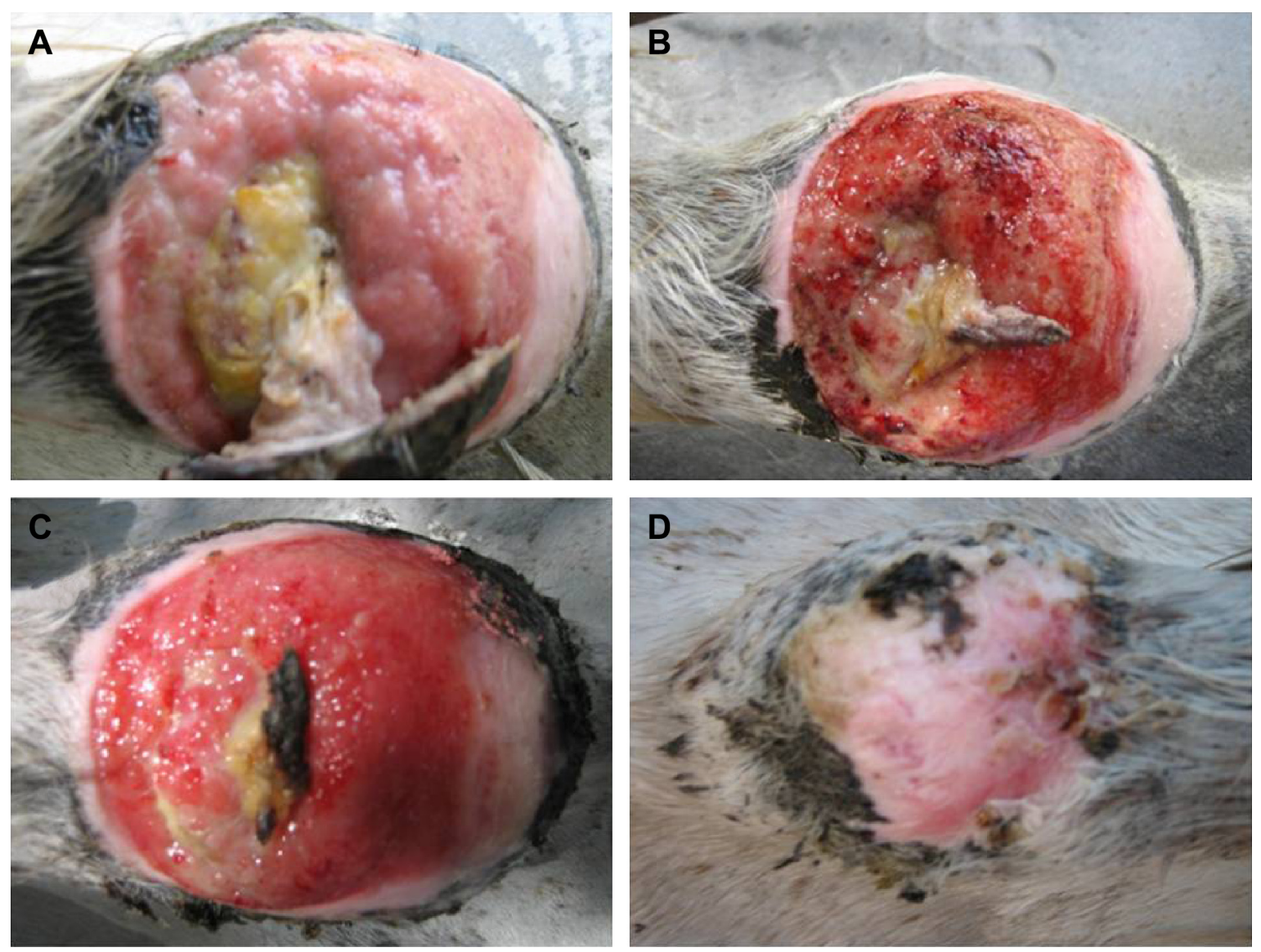

Figure 5 Efficiency of the combined therapy of silver nanoparticles (AgNPs) with blue light in the treatment of antibiotic-unresponsive chronic wound in an infected horse. Notes: A 13-year-old female thoroughbred horse suffering antibiotic-unresponsive chronic skin wound on its back was treated with AgNPs in combination with blue light. The photos show the wound before treatment (A), and after I (B), 2 (C), and 4 weeks (D) of treatment. Note that the wound completely healed after 4 weeks of treatment.

\section{Efficacy of the combined therapy of AgNPs with blue light in the treatment of antibiotic-unresponsive chronic wound in an infected horse}

Three types of bacteria were isolated from the wound, including methicillin-sensitive Staphylococcus aureus, catalase-negative Gram-positive cocci, and $P$. aeruginosa. Signs of improvement following treatment with the combined therapy were observed after 1 week where the tissues partially healed and the amount of exudates decreased. The condition further improved after 2 weeks of continuous treatment and the wound was free from infection. The wound completely healed after 4 weeks and, therefore, the treatment was stopped. The animal was then followed up for another month to monitor possible relapse of the infection (Figure 5).

\section{Discussion}

Nanosized silver is finding increasing attention in medical applications as a promising biocide against a wide range of infections.
A clinical isolate of $P$. aeruginosa was selected as a model Gram-negative bacterium to evaluate the combined therapy utilized in this study; this isolate has probably developed constitutive resistance to several classes of antibiotics, actively formed a biofilm on catheters and implants in a health care setting, and did not respond to any of the available antimicrobial agents. The successful treatment of infections caused by $P$. aeruginosa remains poor with a crude mortality rate of as high as $50 \% .{ }^{15-17}$ Pseudomonas resistance was even demonstrated with the use of antibiotic combinational therapy, which in many reported cases was proven ineffective against MDR strains, especially those which grow in the biofilm. ${ }^{18}$ With the current situation of emergence of bacterial multidrug resistance to most available antibiotics, searching for nonconventional antibacterial agents becomes mandatory. AgNPs are potential antimicrobial agents, which can be considered as an alternative to antibiotics for the treatment of infections caused by MDR bacteria. ${ }^{19}$ They have been used as antimicrobial agents against a wide range of pathogens, including 
Gram-negative and Gram-positive bacteria, viruses, fungi, and nematodes..$^{20-22}$

The reported broad-spectrum antimicrobial activity of AgNPs has been attributed to a combined effect between their physical properties and the released free silver ions. ${ }^{23}$

The tested isolate, however, showed exceptionally low susceptibility to the AgNPs with MIC and MBC as high as $8,000 \mu \mathrm{g} / \mathrm{mL}$. P. aeruginosa was previously shown to be more resistant to AgNPs compared to other Gram-negative bacteria. ${ }^{24} \mathrm{~A}$ significant improvement of the bactericidal activity was observed when the cultures were treated with AgNPs at their MIC with concurrent exposure to blue light for 2 hours, compared to each of them alone (Figure 1). The combined therapy resulted in complete killing of all bacteria after 2 hours, which is significantly faster than the time needed by either agent alone (6 hours). A similar effect was observed when AgNPs were tested in the combination at $1 / 2$ and 1/4 MIC, but with extension of the time needed to completely kill the bacteria (4 and 6 hours, respectively).

The mechanism of the antimicrobial effect of either AgNPs or blue light is still not fully understood. Several theories have been postulated to explain such mechanisms. Many studies have reported that AgNPs can damage cell membranes in Gram-negative bacteria leading to structural changes, which render bacteria more permeable. ${ }^{25,26}$ AgNPs have unique optical, electrical, and thermal properties with a high surface area to volume ratio resulting in the optimal possible interaction with bacterial surfaces leading to a higher antimicrobial activity (Morones et al, 2005). ${ }^{27}$ Cationic silver is released from the nanoparticles when they are dissolved in water or when they penetrate into the cells. ${ }^{16}$ Silver ions bind to the cellular membranes, proteins, and nucleic acids, causing structural changes and deformations of the bacterial cell. ${ }^{19}$ They also deactivate many vital enzymes by interaction with thiol groups ${ }^{28}$ and are involved in the generation of reactive oxygen species. ${ }^{29}$ For blue light, the commonly accepted hypothesis is the production of highly cytotoxic reactive oxygen species in a similar manner to photodynamic therapy. ${ }^{30}$

Genes encoding blue light sensory proteins, such as the light, oxygen, or voltage histidine kinase, have been reported in nonphotosynthetic bacteria, for example, Pseudomonas syringae and Pseudomonas putida. ${ }^{31}$ Although the biological roles of these proteins are largely unknown in pathogenic bacteria, they are believed to regulate the swarming motility in response to blue light. In $P$. aeruginosa, a cross-talk between light, oxygen, or voltage and the bacteriophytochrome BphB is suggested. ${ }^{32}$
A possible mechanism of the observed toxicity of the combinational therapy in this study could be the transduction of the captured blue light energy to the AgNPs resulting in the thermal destruction of the bacterial cells.

The effect of AgNPs and blue light, alone and in combination, on the bacteria was visualized by using TEM (Figure 2). At zero time, most of AgNPs adhered to and accumulated at the bacterial surfaces (Figure 2A), while 2 hours of exposure to a combination of both agents resulted in the appearance of several clumps of AgNPs inside the cells (Figure 2B). AgNPs probably enter the microbial cell by simple diffusion causing the damage of its intracellular structures. When both agents were combined, the damage was significant, demonstrated by perforation of the cell wall, genomic fragmentation, and cell lysis (Figure 2C). A limited effect was observed when $P$. aeruginosa was exposed to blue light (Figure 2D) or the silver compound alone, where the majority of the bacteria remained intact. This supports our finding that synergy is demonstrated in the combination of both agents.

$P$. aeruginosa is among the most common Gram-negative bacteria responsible for biofilm-associated infection. ${ }^{33}$ Bacteria in the biofilms can be up to 1,000 times more resistant to antibiotics than the equivalent planktonic. ${ }^{34}$ Such resistance is demonstrated not only toward antibiotics but also preservatives, disinfectants, and antiseptics. ${ }^{35,36}$ In a medical setting, biofilm-associated infections constitute a steadily increasing problem and can occur on the surfaces of different indwelling devices. Silver has been used to coat plastic catheters and other medical devices to inhibit bacterial colonization. ${ }^{37-39}$

The ability of the combined therapy to prevent colonization and biofilm formation by $P$. aeruginosa on AgNPs impregnated gelatin-based bioplastic discs was assessed. Gelatin was used as a model because it is a natural, nontoxic, and nonimmunogenic material. The fact that it is biodegradable makes it suitable for manufacturing of catheters, which means that it is easily absorbed and no further surgical intervention is required following catheterization. The amount of AgNPs that was released from the disc over a total period of 2 weeks was approximately $25 \%$ of the total loaded amount (results not shown). AgNPs showed sustaining release from the cross-linked matrix as a result of gelatin swelling when it imbibes water. This causes the slow diffusion of the silver particles from the swollen matrix allowing thereby a longer period of colonization prevention.

Blue light alone had no effect on biofilm formation by $P$. aeruginosa compared to drug-free and blue light untreated discs (Figure 3). Biofilm formation was significantly 
inhibited $(P<0.001)$ on AgNP-impregnated discs that were exposed to blue light $\left(\log _{10} \mathrm{CFU}\right.$ reduction $\left.=9.80\right)$ compared to the AgNPs alone $\left(\log _{10}\right.$ CFU reduction $\left.=7.99\right)$.

The demonstrated in vitro antimicrobial synergy between blue light and AgNPs was further investigated in vivo. The combined therapy was evaluated in prevention of infection of burn wound and sepsis by P. aeruginosa in a murine model. Burns are one of the most common and devastating forms of trauma, and most deaths in severely burn-injured patients are still due to burn wound sepsis. ${ }^{40}$ The antimicrobial activity of the silver compound alone and in combination with blue light was compared to that of silver sulfadiazine, which is listed by the World Health Organization as an essential antiinfective topical medicine. ${ }^{41}$ The experiment was performed by measuring the bacterial load in the burn wound, and the degree of bacterial dissemination was measured by taking samples from the liver, lungs, and kidneys. The combined therapy significantly $(P<0.001)$ reduced the number of bacteria in the wound compared to other treatments. However, all treatments failed to diminish dissemination of the infection to the internal organs, except to the liver (Figure 4).

Management of a chronic wound - defined as a barrier defect that has not healed in 3 months - has become a major therapeutic challenge to clinicians. ${ }^{42}$ The incidence, cost, morbidity, and mortality associated with nonhealing chronic skin wounds are dramatic. ${ }^{43}$ Horse wounds are easy to catch bacteria from their surrounding environment. Infected wounds harbor diverse populations, which can be difficult to identify and fail to respond to antibiotic treatment, resulting in chronic nonhealing wounds. ${ }^{44}$

The presented case of the infected horse was selected to test the combined therapy because conventional antibiotic treatment failed to treat the chronic wound caused by mixed infection. S. aureus, Streptococcus spp., and P. aeruginosa were recovered from the swabs that were taken from the wound. These bacterial pathogens are commonly associated with skin infections in horses as single or mixed populations. ${ }^{44,45}$

The treatment protocol establishes an effective and reproducible combinatorial therapy comprising both AgNPs and a simultaneous exposure to blue light (Figure 5). After application and drying, the gel-based medication acted as a shield against any sort of contamination caused by dirt, dust, or flies.

\section{Conclusion}

Synergistic antimicrobial and antibiofilm activities were demonstrated when AgNPs were used in combination with blue light against $P$. aeruginosa in vitro. Synergy was also proved in vivo through treatment of a case of chronic wound caused by mixed infection in a horse. To our knowledge, this combination therapy has not been investigated before. It was proved efficient and promising in managing infections caused by MDR bacteria in vitro and in vivo and could be used as an alternative to conventional antibiotic therapy.

\section{Disclosure}

The authors report no conflicts of interest in this work.

\section{References}

1. Mahendra R, Alka Y, Aniket G. Silver nanoparticles as a new generation of antimicrobials. Biotechnol Adv. 2009;27:176-183.

2. D'Britto V, Kapse H, Babrekar H, et al. Silver nanoparticle studded porous polyethylene scaffolds: bacteria struggle to grow on them while mammalian cells thrive. Nanoscale. 2011;3(7):2957-2963.

3. Nowack B, Krug H, Height M. 120 years of nanosilver history: 609 Implications for policy makers. Environ Sci Technol. 2011;45(4): $1177-1183$.

4. Bogumiła R, Andrea H. Andreas L, Kenneth AD, Iseult L. Mechanisms of silver nanoparticle release, transformation and toxicity: A critical review of current knowledge and recommendations for future studies and applications. Materials. 2013;6:2295-2350.

5. Xiu ZM, Zhang QB, Puppala HL, Colvin VL, Alvarez PJJ. Negligible particle-specific antibacterial activity of silver nanoparticles. Nano Lett. 2012;12(8):4271-4275.

6. Dai T, Gupta A, Murray CK, Vrahas MS, Tegos GP, Hamblin MR. Blue light for infectious diseases: Propionibacterium acnes, Helicobacter pylori, and beyond? Drug Resist Updat. 2012;15(4):223-236.

7. Maclean M, McKenzie K, Anderson JG, Gettinby G, MacGregor SJ. $405 \mathrm{~nm}$ light technology for the inactivation of pathogens and its potential role for environmental disinfection and infection control. $J$ Hosp Infect. 2014;88(1):1-11.

8. Filice GA, Nyman JA, Lexau C, et al. Excess costs and utilization associated with methicillin resistance for patients with Staphylococcus aureus infection. Infect Control Hosp Epidemiol. 2010;31(4):365-373.

9. Mauldin PD, Salgado CD, Hansen IS, Durup DT, Bosso JA. Attributable hospital cost and length of stay associated with health care-associated infections caused by antibiotic-resistant Gram-negative bacteria. Antimicrob Agents Chemother. 2010;54(1):109-115.

10. Métraux GS, Mirkin CA. Rapid thermal synthesis of silver nanoprisms with chemically tailorable thickness. Adv Mater. 2005;17(4):412-415.

11. Kapoor S. Preparation, characterization, and surface modification of silver particles. Langmuir. 1998;14(5):1021-1025.

12. Clinical Laboratory Standard Institute (CLSI). Reference Method for Broth Dilution Antifungal Susceptibility Testing of Yeasts; Approved Standards-Second Edition, in CLSI document M27-2A. Pennsylvania, USA: CLSI; 2002.

13. Dykstra MJ, Reuss E. Biological Electron Microscopy Theory, Techniques and Troubleshooting. 2nd ed. Germany: Springer; 2003.

14. Rupal J, Kausha J, Mallikarjuna SC, Dipt P. Preparation and evaluation of topical gel of valdecoxib. Int J Pharm Sci Drug Res. 2010;2(1): $51-54$.

15. Bisbe J, Gatell JM, Puig J, et al. Pseudomonas aeruginosa bacteremia: univariate and multivariate analyses of factors influencing the prognosis in 133 episodes. Rev Infect Dis. 1988;10:629-635.

16. Vidal F, Mensa J, Almela M, et al. Epidemiology and outcome of Pseudomonas aeruginosa bacteremia, with special emphasis on the influence of antibiotic treatment. Analysis of 189 episodes. Arch Intern Med. 1996;156:2121-2126.

17. Tamma PD, Cosgrove SE, Maragakis LL. Combination therapy for treatment of infections with Gram-negative bacteria. Clin Microbiol Rev. 2012;25:450-470 
18. Hill D, Rose B, Pajkos A, et al. Antibiotic susceptibilities of Pseudomonas aeruginosa isolates derived from patients with cystic fibrosis under aerobic, anaerobic, and biofilm conditions. $J$ Clin Microbiol. 2005;43(10):5085-5090.

19. Franci G, Falanga A, Galdiero S, et al. Silver nanoparticles as potential antibacterial agents. Molecules. 2015;20:8856-8874.

20. Elechiguerra JL, Burt JL, Morones JR, et al. Interaction of silver nanoparticles with HIV-1. J Nanobiotechnology. 2005;3:6.

21. Cromwell WA, Yang J, Starr JL, Jo YK. Nematicidal effects of silver nanoparticles on root-knot nematode in bermudagrass. J Nematol. 2014; 46(3):261-266.

22. Pereira L, Dias N, Carvalho J, Fernandes S, Santos C, Lima N. Synthesis, characterization and antifungal activity of chemically and fungalproduced silver nanoparticles against Trichophyton rubrum. J Appl Microbiol. 2014;117(6):1601-1613.

23. Choi O, Hu Z. Size dependent and reactive oxygen species related nanosilver toxicity to nitrifying bacteria. Environ Sci Technol. 2008;42: 4583-4588.

24. Zhang M, Zhang K, De Gusseme B, Verstraete W, Field R. The antibacterial and anti-biofouling performance of biogenic silver nanoparticles by Lactobacillus fermentum. Biofouling. 2014;30:347-357.

25. Lazar V. Quorum sensing in biofilms - How to destroy the bacterial citadels or their cohesion power? Anaerobe. 2011;17:280-285.

26. Periasamy S, Joo HS, Duong AC, et al. How Staphylococcus aureus biofilms develop their characteristic structure. Proc Natl Acad Sci. 2012; 109:1281-1286.

27. Morones JR, Elechiguerra JL, Camacho A, et al. The bactericidal effect of silver nanoparticles. Nanotechnology. 2005;16:2346-2353.

28. Matsumura Y, Yoshikata K, Kunisaki S, Tsuchido T. Mode of bacterial action of silver zeolite and its comparison with that of silver nitrate. Appl Environ Microbiol. 2003;69:4278-4281.

29. Sukumaran P, Eldho KP. Silver nanoparticles: mechanism of antimicrobial action, synthesis, medical applications, and toxicity effects. Int Nano Lett. 2012;2:32.

30. Maclean M, Macgregor SJ, Anderson JG, Woolsey GA. The role of oxygen in the visible-light inactivation of Staphylococcus aureus. J Photochem Photobiol B. 2008;92(3):180-184.

31. Wu L, McGrane RS, Beattie GA. Light regulation of swarming motility in Pseudomonas syringae integrates signaling pathways mediated by a bacteriophytochrome and a LOV protein. MBio. 2013;4(3): e00334-e13.
32. Barkovits K, Schubert B, Heine S, Scheer M, Frankenberg-Dinkel N. Function of the bacteriophytochrome BphP in the RpoS/Las quorum sensing network of Pseudomonas aeruginosa. Microbiology. 2011; 157(Pt 6):1651-1664.

33. Donlan RM, Costerton JW. Biofilms: Survival mechanisms of clinically relevant microorganisms. Clin Microbiol Rev. 2002;15:167-193.

34. Moskowitz SM, Foster JM, Emerson J, Burns JL. Clinically feasible biofilm susceptibility assay for isolates of Pseudomonas aeruginosa from patients with cystic fibrosis. J Clin Microbiol. 2004;42:1915-1922.

35. Costerton JW, Stewart PS, Greenberg EP. Bacterial biofilms: a common cause of persistent infections. Science. 1999;284(5418):1318-1322.

36. Scher K, Romling U, Yaron S. Effect of heat, acidification, and chlorination on Salmonella enterica serovar typhimurium cells in a biofilm formed at the air-liquid Interface. Appl Environ Microbiol. 2005;71(3): $1163-1168$

37. Roe D, Karandikar B, Bonn-Savage N, Gibbins B, Roullet JB. Antimicrobial surface functionalization of plastic catheters by silver nanoparticles. J Antimicrob Chemother. 2008;61:869-876.

38. Stevens KN, Croes S, Boersma RS, et al. Hydrophilic surface coatings with embedded biocidal silver nanoparticles and sodium heparin for central venous catheters. Biomaterials. 2011;32:1264-1269.

39. Mahmoudi M, Serpooshan V. Silver-coated engineered magnetic nanoparticles are promising for the success in the fight against antibacterial resistance threat. ACS Nano. 2012;6:2656-2664.

40. Church D, Elsayed S, Reid O, Winston B, Lindsay R. Burn wound infections. Clin Microbiol Rev. 2006;19(2):403-434.

41. World Health Organization (WHO) Model List of Essential Medicines, 19th list; 2015. Available from: http://www.who.int/medicines/ publications/essentialmedicines/en/. Accessed November 10, 2015.

42. Nunan R, Harding KG, Martin P. Clinical challenges of chronic wounds: searching for an optimal animal model to recapitulate their complexity. Dis Model Mech. 2014;7(11):1205-1213.

43. Zhao G, Usui ML, Lippman SI, et al. Biofilms and inflammation in chronic wounds. Adv Wound Care. 2013;2(7):389-399.

44. Westgate SJ, Percival SL, Knottenbelt DC, Clegg PD, Cochrane CA. Microbiology of equine wounds and evidence of bacterial biofilms. Vet Microbiol. 2011;12:150-152.

45. Fjordbakk CT, Arroyo LG, Hewson J. Retrospective study of the clinical features of limb cellulitis in 63 horses. Vet Rec. 2008;162(8):233-236.
International Journal of Nanomedicine

\section{Publish your work in this journal}

The International Journal of Nanomedicine is an international, peerreviewed journal focusing on the application of nanotechnology in diagnostics, therapeutics, and drug delivery systems throughout the biomedical field. This journal is indexed on PubMed Central, MedLine, CAS, SciSearch $®$, Current Contents ${ }^{\circledR} /$ Clinical Medicine,

\section{Dovepress}

Journal Citation Reports/Science Edition, EMBase, Scopus and the Elsevier Bibliographic databases. The manuscript management system is completely online and includes a very quick and fair peer-review system, which is all easy to use. Visit http://www.dovepress.com/ testimonials.php to read real quotes from published authors. 